\title{
"Absenteísmo no atendimento clínico-odontológico: o caso do Módulo de Serviço Comunitário (MSC) do Centro de Pesquisas em Odontologia Social (CPOS) - UFRGS"
}

\author{
"Absenteeism in clinical dental treatment: the case of a Community Dental \\ Service (MSC) - UFRGS dentistry school"
}

Circe Maria Jandrey **

Tania Maria Drehmer ***

\section{RESUMO}

O Módulo de Serviço Comunitário (MSC) do Centro de Pesquisas em Odontologia Social (CPOS) é um dos ambientes onde se realiza o Estágio em Saúde Pública II, atividade curricular obrigatória para alunos do oitavo semestre da Faculdade de Odontologia da Universidade Federal do Rio Grande do Sul. Seu financiamento é obtido mediante convênio com o SUS com vistas ao atendimento odontológico de escolares da região. Os estagiários realizam um programa educativo-preventivo de saúde bucal nas escolas e, ao identificarem necessidades curativas em tais escolares, os mesmos são encaminhados, com agendamento prévio, ao MSC para atendimento integral e gratuito. No entanto, um expressivo absenteísmo, (em torno de 45\%), tem sido verificado ao longo dos anos. Este estudo teve como objetivo identificar os motivos pelos quais isto ocorre. Foram entrevistadas 59 crianças/adolescentes, todas regularmente matriculadas em escolas estaduais integrantes do programa docente-assistencial. Desse total, 24 não haviam comparecido ao atendimento no dia marcado. Complementarmente às entrevistas com os escolares, foram efetuadas 48 visitas a famílias de entrevistados, contemplando ausentes e presentes ao atendimento, com o intuito de melhor compreender a realidade da população estudada. Do ponto de vista qualitativo, o material coletado foi submetido a uma análise de seu conteúdo; entre os motivos concorrentes para o fenômeno, destacam-se sentimentos como medo e ansiedade ao atendimento odontológico, o tipo de percepção que a clientela tem a respeito de serviços de saúde e o significado que cuidados com saúde e, especificamente com saúde bucal, assumem junto a esta comunidade; identificou-se o absenteísmo como a manifestação, a nível dos serviços odontológicos, de um processo maior, qual seja, o de exclusão social que, por sua vez, permeia toda a sociedade.

\section{UNITERMOS}

Absenteísmo, avaliação de programas, exclusão social

\section{INTRODUCẼO E REVISÃO DA LITERATURA}

A saúde de uma comunidade é um processo dinâmico e contraditório, resultante da confluência de fatores como políticas econômicas e sociais, desenvolvimento científico, de processos técnicos, formação da força de trabalho em saúde e de mutações no mercado de trabalho em saúde ${ }^{1}$. O MSC mantém uma relação de trabalho com escolas públicas estaduais de ensino fundamental da comunidade do pericampus do Vale, distante cerca de vinte quilômetros do centro de Porto Alegre ${ }^{26 .}$. Esta relação de trabalho tem se modificado ao longo do período, especialmente, quanto à ampliação do número de instituições atendidas, mantendo-se, no entanto, inalterada sua feição de propor atividades que contemplem a integração docente-assistencial. Realizase, assim, um programa conjunto entre MSC e Estágio de Saúde Pública II (ESP II), estágio curricular do Curso de Odontologia. Acadêmicos do oitavo semestre efetuam, nas próprias escolas, atividades educativas e preventivas com alunos das instituições integrantes da rede de atendimento do MSC. Constatadas necessidades curativas, estes escolares são referenciados ao serviço, com dia e hora marcados, para atendimento clínico pelo acadêmico que os contactou na escola, estabelecendo-se, assim, vínculo entre profissional (acadêmico) e clientela.

Nesta atividade, identificaram-se problemas; dentre esses, um expressivo absenteísmo dos usuários do serviço. Relatórios entregues pelos acadêmicos ao final de seu estágio apontaram que, no segundo semestre de 1997, o absenteísmo atingiu $45,90 \%$ dos encaminhados ao atendimento. Absenteísmo, em serviço que trabalha com agendamento prévio, se constitui em problema, quer do ponto de vista do planejamento/gerenciamento ou sob um enfoque didático-metodológico, pela ociosidade da capacidade instalada, baixa cobertura, manutenção de segmentos desassistidos ${ }^{7,22}$ e frustração para com uma prática que objetiva a integralidade das ações em saúde bucal.

Desse modo, a proposição deste estudo foi verificar e compreender os motivos pelos quais se manifesta o absenteísmo no atendimento clínico odontológico ao confrontar a prática estabelecida pelo MSC com a dinâmica das condições de vida da comunidade.

Estudos mostram que desigualdades sociais levam a prejuízos nos padrões sanitários 3,4,10,15,19,25. Quanto maiores os níveis de pobreza, menor o efeito protetor dos serviços de saúde ${ }^{8,11}$, observando-se, também, que comunidades desfavorecidas tendem a sofrer um processo de marginalização ${ }^{13}$, aliando-se, nesses indivíduos, a crença de que os serviços existentes não são para eles ${ }^{20,23,24}$. Resistências institucionais (como horários

\footnotetext{
* Resumo da dissertação apresentada ao PPG-Odontologia - Saúde Bucal Coletiva para obtenção do título de Mestre

** Cirurgiã-dentista - Especialista em Saúde Coletiva

***Cirurgiã-dentista - Doutora em Saúde Pública- Orientadora
} 
pouco flexíveis e o tipo de acolhimento dado ao usuário) e a exigência de uma conduta racional frente à doença podem influenciar no acesso ${ }^{12,13}$ e utilização de serviços de saúde ${ }^{14,16,18,28}$. Outros aspectos apontados pela literatura referem-se aos distintos sentimentos e percepções que as diferentes classes sociais têm em relação ao corpo ${ }^{5,6}$ bem como a grande angústia e medo de parcelas da população diante da necessidade de uma visita ao dentista ${ }^{5,21}$. A literatura enfatiza a necessidade da prática odontológica construir novos espaços que atinjam o coletivo e a família ${ }^{29}$.

Tradicionalmente, os serviços públicos de saúde brasileiros se organizam em livre demanda, apresentando insuficiência de vagas; por essa razão, o absenteísmo não se constitui em problema e, consequientemente, não é estudado. Devido à escassez ou indisponibilidade de informações sobre o tema, optou-se por buscar esse conhecimento no campo da educação, posto que, como prática social, esta apresenta pontos em comum com a saúde ${ }^{10}$. A ausência à escola compõe o processo de exclusão escolar ${ }^{2,17}$, que, por sua vez, integra o processo maior de exclusão social definida como o não acesso a uma série de direitos básicos (alimentação, trabalho, moradia, entre outros), inscritos ou não na legislação de um país ${ }^{27}$.

\section{MATERIAIS E MÉTODOS}

A área estudada compreende dois bairros populares da cidade de Porto Alegre, limítrofes com o município de Viamão. 0 local é bastante arborizado e populoso, com grande número de moradias do tipo barracos. A população deste estudo é composta por alunos entre 6 e 17 anos de idade, regularmente matriculados em turnos diurnos das escolas atendidas pelo MSC.

A amostra estudada foi composta por 59 alunos entrevistados em suas escolas de origem, 35 presentes ao serviço clínico e 24 ausentes. A diferença numérica entre os dois grupos se explica pelo fato de que os ausentes ao agendamento também se mostraram menos frequientes à escola na semana seguinte ao evento. $O$ período de coleta de dados esteve compreendido entre agosto e dezembro de 1998, encerrando-se com o término do ano letivo das escolas estaduais devido à suspensão dos encaminhamentos.

Com as informações sobre os encaminhamentos registradas, semanalmente, pelos acadêmicos numa planilha específica, realizou-se, ao final de cada sexta-feira do período, um sorteio, sem reposição, da escola a ser visitada na semana seguinte. Foram igualmente sorteados, dentre os escolares entrevistados, aqueles que receberiam a visita domiciliar. Uma vez visitadas todas as escolas, reiniciou-se o processo de sorteios.

Foram efetuadas, desse modo, 48 visitas domiciliares para entrevistar os responsáveis pelos escolares. Todas as visitas foram realizadas, invariavelmente, pela pesquisadora e na semana subsequiente à presença/ausência ao MSC. Em média, buscou-se estabelecer 4 visitas domiciliares a cada semana: 2 a familiares de encaminhados presentes e 2 aos de encaminhados faltosos.

Foram utilizados como métodos de investigação, mediante consentimento prévio dos integrantes do estudo: entrevistas, registro visual (fotografias), tomada de depoimentos, bem como observação participante e notas de campo. A análise dos dados foi efetuada, num primeiro momento, considerando os elementos quantitativos recolhidos, os quais compuseram um perfil da população estudada. Como a forma predominante de coleta de dados foi a tomada de entrevistas/depoimentos, realizou-se a transcrição dos mesmos; o material transcrito foi submetido a uma análise de seu conteúdo através de sucessivas leituras e discussões, possibilitando a descrição dos sujeitos e seus discursos sobre o fenômeno pesquisado ${ }^{9,23}$.

\section{RESULTADOS E DISCUSSÃO}

O absenteísmo ao MSC, no segundo semestre de 1998 , atingiu $41,60 \%$ dos encaminhados ao serviço, guardando semelhança com o percentual registrado um ano antes e que já vinha sendo observado há mais tempo.

Os resultados das entrevistas mostraram que, em respeito às condições de vida, os grupos estudados apresentamse homogêneos quanto às seguintes características:

- baixa renda familiar $(49,16 \%$ da amostra com renda de até 4 salários mínimos)

- parcela considerável das famílias vivem em barracos/área invadida ou casa cedida $(44,07 \%$ dos entrevistados relatam ter estas condições de habitação).

Ainda que, no seu conjunto, os responsáveis pelos entrevistados se apresentem pouco escolarizados $(66,08 \%$ dos pais e $74,56 \%$ das mães não concluíram o ensino fundamental completo), tal escolaridade foi maior entre os responsáveis daqueles que estiveram presentes ao serviço (associação estisticamente significativa ao nível de 5\%).Apenas um pai,
$1,69 \%$ do total, referiu escolaridade superior e, ainda assim, incompleta, o que não foi observado para nenhuma mãe.

Quanto à ocupação destes responsáveis, $46,67 \%$ dos pais de ausentes referiram inserção informal no mercado de trabalho (associação estatisticamente significativa ao nível de 5\%), ou seja, sem garantia de renda, percentual que atinge 54,23 das mães dos escolares.

Tais achados corroboram a colocação de autores já referidos ${ }^{3,4}$ de que renda e escolaridade determinam as condições de vida das comunidades, ainda que, neste estudo, a renda familiar declarada não tenha sido estatisticamente diferente entre os dois grupos. Observou-se, por exemplo, que a ausência de renda fixa devido à inserção informal dos responsáveis no mercado de trabalho parece associar-se à inexistência de uma conduta racional frente à doença, assim como à crença de que os serviços de saúde disponíveis não são para eles. Estes fatos parecem vincular-se ao acesso e utilização desses mesmos serviços.

A análise das entrevistas dos escolares e depoimentos dos responsáveis possibilitou compreender que os motivos expressados nem sempre justificaram as ausências ao atendimento. Previamente a este estudo, a falta de passagens e a distância casa-MSC eram tidas, pela equipe técnica do serviço, como responsáveis pelas ausências; no entanto, a distribuição dos faltosos da amostra pesquisada segundo motivo da ausência expressado pela criança/ adolescente mostra que estas situações compreenderam, cada uma respectivamente, $2(8,33 \%)$ e $1(4,17 \%)$ do total das respostas (Tabela). Ao estabelecerse a entrevista com os responsáveis, verificou-se que a falta de passagens apontada pelos escolares poderia ter sido solucionada, em um dos casos, realizando o percurso até o MSC a pé, (o que era rotineiramente feito por esta entrevistada para chegar à sua escola, situada ao lado do serviço); para a outra respondente na mesma condição, foi possível observar, segundo o relato da sua responsável, que as passagens poderiam ter sido providenciadas, desde que a mesma soubesse com maior antecedência. A distância casa-serviço, apontada somente por um entrevistado, foi efetivamente observada neste caso, dado que, segundo informações proveniente da secretaria da escola, o jovem, cuja família mudara de residência durante o período letivo, já estava com sua transferência programada para outra instituição, próxima à sua nova moradia, ao final de 1998. 
TABELA

\section{DISTRIBUIÇÃO DOS FALTOSOS DA AMOSTRA PESQUISADA SEGUNDO MOTIVO DA AUSÊNCIA EXPRESSADO PELA CRIANÇA/ ADOLESCENTE. POA. RS.1998}

\begin{tabular}{lcc}
\hline MOTIVO & $\begin{array}{c}\text { NÚMERO DE } \\
\text { AUSENTES }\end{array}$ & $\%$ \\
\hline ESQUECIMENTO/PERDA HORÁRIO & 7 & 29,17 \\
RESPONSÁVEL NÃO POODE ACOMPANHAR & 6 & 25,00 \\
RESPONSÁVEL DOENTE & 2 & 8,33 \\
SEM PASSAGEM & 2 & 8,33 \\
CUIDAR DE IRMÃO & 1 & 4,17 \\
DISTÂNCIA CASA/MSC & 1 & 4,17 \\
RESPONSÁVEL DESCONHECIA MARCAÇÃO & 1 & 4,17 \\
NÃO SOUBE INFORMAR & 1 & 4,17 \\
PERDA DO CARTÃO DE AGENDAMENTO & 1 & 4,17 \\
NECESSIDADE DE FAZER COMPRAS & 1 & 4,17 \\
NĀO ENTREVISTADO & 1 & 4,17 \\
\hline TOTAL & 24 & 100,00 \\
\hline
\end{tabular}

Em verdade, o medo ao atendimento odontológico é uma emoção que apareceu como pano de fundo, no cotidiano das vivências contextualizadas, seja em relação aos escolares ou aos responsáveis, tanto para presentes como para ausentes ao MSC. São relatos oriundos de entrevistas:

"... falar em dentista prá mim é uma tristeza...eu tenho mais medo que as crianças; nunca aconteceu nada, só aquela 'injeçãozinha', aquela agulha...falar em dentista, eu me arrepio tudo...eu nem disse que eu tenho medo e o pai deles é a mesma coisa... por isso que eu digo prá eles, quando marcar, vocês têm que ir, depois mais tarde vocês tão com os dente tudo podre, tem que fazer chapa, ponte..." (mãe de Cátia, aluna presente ao atendimento)

"...tenho medo...trauma...bah, pelo amor de Deus, não quero nem me lembrar, tenho trauma mesmo, me judiaram, me levaram a força, daí eu fiquei com medo; não tenho ido seguido, não...nunca falei, senão ele vai ficar com medo, esse (referindo a Michael) sempre gostou de ir no dentista..."

( mãe de Michael, aluno presente ao atendimento)

O maior número de respostas "esquecimento/perda de horário" apontado pela Tabela também pode estar relacionado a esse sentimento, justificando-se, desse modo, em vários momentos, a ausência aos agendamentos.

“...ir ao dentista é uma coisa ruim, eu tremo só de sentar na cadeira, dá mais medo que parto..." (mãe de Anderson, aluno ausente ao atendimento)

"... é horrível, foi ruim, eu não gosto, eu morro de medo de dentista, não me trataram mal, eu é que si mesmo, eu tenho medo. Foi na Santa Casa; pode ser o mais gentil do mundo, eu tenho medo...eu nunca tive medo, depois de grande é que eu fiquei com medo..." (mãe de Valéria, aluna ausente ao atendimento)

O material transcrito oportunizou perceber que, para uma parcela desta população, cuidados com saúde bucal não têm significado consistente, salvo na situaçãolimite de dor, o que também é apontado pela literatura 5,13,14,16. Registrou-se, neste estudo, associação estatisticamente significativa ao nível de 5\% entre experiência de dor no período de marcação e comparecimento ao serviço. Igualmente, observaram-se, em alguns casos, descrédito e aversão completa a toda forma de assistência odontológica. Estes elementos, aliados ao medo, podem levar ao absenteísmo e integram o processo de exclusão social que permeia a comunidade estudada. Isto é exemplificado através dos depoimentos que seguem:

“...é difícil prá pagar, de graça é mesmo que nada, bota uma obturação, chega em casa, já não tem mais, já caiu no ônibus, é bem isso aí...prá pagar, a gente não tem dinheiro, e de graça, não adianta de nada; além de ser dificil, esses do INPS, dos posto, é mesmo que nada, às vezes até pagando, a gente chega em casa e já tá caindo tudo..." (mãe de Leandro C., aluno ausente ao atendimento)

"...começou a estragar, já tirei tudo de uma vez prá não me incomodar...eu acho assim: é melhor tirar que deixar arrumar, senão começa a doer de novo...doía na hora, mas depois deu, nunca mais tinha dor de dente... a gente arruma, depois dói, tem que arrumar de novo, pega, já tira o dente e deu..." (mãe de Denise P., aluna ausente ao atendimento).

Outro aspecto identificado, através da análise de conteúdo do material discursivo, foi o de que a racionalidade deste serviço odontológico, tal qual ocorre em outras instituições, ainda se encontra pautada mais pelos interesses institucionais do que pela compreensão do seu efetivo papel frente à comunidade. A lógica do atendimento, em especial no que diz respeito a horários e grupos populacionais atendidos, também parece ser, em certa medida, um fator coadjuvante para que as ausências ocorram. Não há, no MSC, qualquer forma de participação popular, sequer a nível consultivo: a população não reconhece 0 serviço como um direito seu, mas como um favor que lhe é prestado. Estas percepções se evidenciam nas falas dos entrevistados:

"...eu brigo muito com ela que ela vem tão tarde, brigo assim de xingar, ela diz que a uma hora (13:00) tem que tá lá, aí chega aqui às cinco, a gente fica meio desconfiada..." (mãe de Cátia)

"...cheguei a uma (13:00) bem dizer e saí de lá às quatro e pouco, mas valeu a pena...eu só tava preocupada porque eu não tinha dado almoço prás crianças, pra nenhum deles e eles começaram a incomodar...eu pensei 'a gente chega ali e vai ser ligeiro'..." (mãe de Elisângela)

“...no caso, é muito difícil a gente conseguir um dentista; então a gente vai assim, quando tem um problema, uma dor de dente ou tem que extrair, tem que dar uma olhada; é muito difícil mesmo. A gente até precisa, mas vai quando é necessário. Necessário é quando tá com dor, porque aí é mais fácil, a gente vai e consulta, tem como consultar; se não tem dor, quer ver uma cárie, uma coisa ou outra, aí tem que marcá pro outro mês, aí não consegue praquele mês, que é três ficha só, então é muito difícil mesmo. Na Mapa, no posto do Sanatório (Centro de Saúde São José do Murialdo), vai vinte pessoa na fila prá três ficha, desse mês pro outro mês ainda, então é muito difícil, não é só prá gente, é de um modo geral..." (pai de Dariane)

“...uma pena que não tem prá adulto, senão, eu ia...é um trabalho muito prestativo, um troço assim, é difícil sabe, porque onde eu morava eu nunca soube disso ali, nunca teve, tinha problema até prá levar no posto as crianças prá tirar os dente, prá arrumar umas coisa assim, tinha que pagar...eu achei um serviço muito bom que lá na minha terra não tinha, não sei se agora, mas nunca teve, era tudo dificil, sabe? Se não tinha dinheiro prá tratar, não tinha dentista..." (avó de Roberta).

Os aspectos apontados nestes relatos parecem contribuir para 0 distanciamento entre comunidade e serviço, o que explicaria a utilização deste último basicamente na situação-limite da dor.

Há também aqueles que aprovam o serviço, principalmente pela sua gratuidade, embora seja possível observar que o recebem como um favor que lhes é 
prestado e não como um direito a ser usufruído. As palavras de alguns entrevistados apontam para esta observação:

“...prá nível de pais que não tem condições de fazer um acompanhamento com a criança sobre dentista, é uma coisa de graça...uma preocupação que os doutor tem com as crianças, procurar na escola as criança que tem dificuldade, que precisam de atendimento, eu achei ótimo, muito bom..." (mãe de Cristina)

“...a opinião é que isso aí serve prás pessoa pobre, que não tem condição de ir no dentista, passa lá e eles atendem e não cobram nada..." (pai-avô de Alessandro)

“...eu gostei, né doutora? Se a gente não der valor pelo que tão fazendo pros filhos da gente...que é que adianta dizer que não gostou? Eu adorei, porque pelo menos não vendo um filho chorar com dor, já é uma tranqüilidade..." (mãe de Fabiano)

Assim, parece ser necessário discutir e readequar a prática do MSC, de modo a que sua estrutura de prestador de serviços à comunidade seja efetivamente orgânica $a$ quem se destina.

\section{CONCLUSÕES}

Ao final deste estudo, do ponto de vista qualitativo, foi possível compreender que $o$ absenteísmo ao MSC não é fruto de um motivo isolado e que vários fatores concomitantes contribuem para a sua manifestação: medo ao atendimento, experiências frustrantes e descrédito na assistência odontológica, assim como a lógica de estruturação dos serviços ao que se alia a inexistência de participação popular. Em verdade, a experiência de dor no período do agendamento é o motivo que, efetivamente, impulsiona a ida ao MSC. Desse modo, garantia de agendamento, para tal comunidade, não configura utilização plena do serviço.

Sob a perspectiva da Saúde Bucal Coletiva, o absenteísmo parece ser uma das expressões do processo de exclusão social em que se encontra essa população, cujos direitos básicos como educação, saúde, habitação, por exemplo, estão escritos na lei, mas não são garantidos pelo Estado. A melhoria das condições de vida dos usuários precede, portanto, o agendamento das consultas como forma de organização dos serviços.

\section{SUMMARY}

A community dental service (MSC), integrating UFRGS Dentistry School is one of the fields where graduate students practice public health actions. The program is financed by Brazilian public health system (SUS), intending to offer dental treatment to schoolchildren from the area. Dentistry students promote educational and preventive actions at public schools and refer those who need curative interventions to MSC. The objective of this study is to identify the reasons for why schoolchildren/adolescents are absent in such dental treatment; fiftynine participants were interviewed, all of them regularly attending public schools covered by the program; among them, twenty-four were absent in dental treatment appointment; in addition to interviews, fourty-eight families were visited, including absents and presents, in order to better understand the reality faced by this population; qualitative and quantitative analyses were conducted showing that several reasons contribute to the phenomenon such as feelings like fear and anxiety, people's perceptions about health services and these people's beliefs and values of oral health; absenteeism was identified as part of a wider social process: the social deprivation which permeates all Brazilian society.

\section{KEYWORDS}

Absenteeism, Program Evaluation, Social Exclusion.

\section{REFERÊNCIAS BIBLIOGRÁFICAS}

1 ACHUTTI, Aloísio. Zero Hora, Porto Alegre, 24-25 dez. 1997. Editorial, p. 8 .

2 ARROYO, Miguel. Da escola carente à escola possível. São Paulo: Loyola, 1992. 183p.

3 BARROS, Fernando; VICTORA, César G. Epidemiologia da saúde infantil: um manual para diagnósticos comunitários. 2.ed. São Paulo : Hucitec,UNICEF, 1994. 178p.

4 BEAL, J. F. Social factors and preventive dentistry: prevention of oral disease. 3.ed. New York: Oxford University Press, 1996. p.216-233.

5 BOLTANSKI, Luc. As classes sociais e o corpo. 3.ed. Rio de Janeiro : Graal, 1989. 191p.
6 BOURDIEU, Pierre. 0 poder simbólico. 2. ed. Rio de Janeiro: Bertrand Brasil. 1998. 322p.

7 CAMPOS, Gastão Wagner de Souza. Desafios para novos modelos de gestão: prioridade é fortalecer a rede básica. Tema Radis, Rio de Janeiro, n. 15, p. 23, 1997.

8 CENTRO DE ESTUDIOS Y ASESORÍA EN SALUD. Mujer, trabajo y salud. Quito, 1994. 370p.

9 Comiotto, Miriam Sirley. Epidemiologia qualitativa: um novo desafio. In: CONGRESSO NACIONAL DA ASSOCIAÇÃO BRASILEIRA DE ODONTOLOGIA DE PROMOÇÃO DE SAÚDE, 9, 1999. Gramado, 1999. Comunicação.

10 DICKSON, Murray. Oral health promotion. In: MAUTSCH, Walter; SHEIHAM, Aubrey. Promoting oral health in deprived communities. Berlin: ZME, 1993. p. 175-187.

11 FAERSTEIN, Eduardo. Um toque de otimismo sobre a epidemiologia contemporânea. Physis: Revista de Saúde Coletiva, Rio de Janeiro, v.7, n.l, p.123-136, 1997.

12 FRENK, Julio. El concepto y la medición de accessibilidad. Salud Publica de Mexico, México, v. 27, n. 5, p. 438-453, sept./oct. 1985.

13 GIACOMAZZI, Maria Cristina. Aspectos do mundo natural entre aqueles que se mobilizam por saúde: idéias e atitudes na vila Lomba do Pinheiro, em Porto Alegre. Porto Alegre: UFRGS, 1993. Dissertação (Mestrado em Antropologia Social) - UFRGS, Instituto de Filosofia e Ciência Humanas, 1993. 216 p.

14 O cotidiano da vila Jardim: um estudo de trajetórias, narrativas biográficas e sociabilidades sob o prisma do medo na cidade. Porto Alegre: UFRGS, 1997. Tese (Doutorado em Antropologia Social) - UFRGS,

Instituto de Filosofia e Ciências Humanas, 1997. 2v.

15 GIFT, Helen. Quality of life - an outcome of oral health care? J. Public Health Dent., Richmond, v.56, n.4, p.67$68,1996$.

16 KNAUTH, Daniela. Os caminhos 
da cura. Porto Alegre: UFRGS, 1991. Dissertação ( Mestrado em Antropologia Social) - UFRGS, Instituto de Filosofia e Ciência Humanas, 1991. 187p.

17 LAHIRE, Bernard. Sucesso escolar nos meios populares: as razões do improvável. São Paulo: Ática, 1997. $367 \mathrm{p}$.

18 LEMOS, Vânia Maria Aita de. Perda dentária e necessidades de prótese em população jovem de uma região agrícola do Rio Grande do Sul - uma análise sócio-epidemiológica. Porto Alegre: UFRGS, 1981. 176p. Dissertação (Mestrado em Odontologia Social ) - UFRGS, Faculdade de Odontologia, 1981.

19 LOCKER, David. Using areabased measures of socioeconomis status in dental health services research. $J$. Public Health Dent., v.56, n.4, p.69-75, 1996.

20 MAUTSCH, Walter; SHEIHAM, Aubrey. Promoting oral health in deprived communities. Berlin: German Fundation for Internacional Development, ZME, 1993. 515p.

21 MAZOCCHI, Nílcia; OLIVEIRA, Renato de. Psicologia e odontologia: ensaio de integração multiprofissional nucleado pela equipe odontológica. In.: CONGRESSO PAULISTA DE SAÚDE PUBLICA. 5, 1997. São Paulo, Águas de Lindóia, 1997. Comunicação.

22 MERHY, Emerson Elias. O SUS e um de seus dilemas: mudar a gestão e a lógica do processo de trabalho em saúde (um ensaio sobre a micropolítica do trabalho vivo). In: FLEURY, Sônia. (Org.) Saúde e democracia: a luta do Cebes. São Paulo : Lemos Editorial, 1997. p. 125143

23 MINAYO, Maria Cecília (Org.). Pesquisa social: teoria, método e criatividade. Petrópolis: Vozes, 1994. 80p.

24 PETERSEN, Poul Erik. Society and oral health In: PINE, Cynthia (Org.)

Community oral health. London: Wright, 1997. p. 20-27.

25 PINE, Cynthia. Introduction, principles and practice of public health. In: PINE, Cynthia (org.) Community oral health. London. Wright, 1997.
26 PIRES FILHO, Fernando Molinos et al. Módulo de serviço comunitário. Revista da Faculdade de Odontologia, Porto Alegre, v.26, p.97-111, 1984.

27 SILVA, Marcelo Kunrath. Cidadania e exclusão: os movimentos sociais urbanos e a experiência de participação na gestão municipal; uma análise da trajetória do movimento da Vila Jardim em Porto Alegre/RS. Porto Alegre: UFRGS, 1997. 286 p. Dissertação (Mestrado em Sociologia) - UFRGS, Instituto de Filosofia e Ciências Humanas, 1997.

28 VELLOZO, Vitória Régia Osório; SOUZA, Rosimary Gonçalves de. Acesso e hierarquização: um caminho (re)construído. In: BODSTEIN, Regina. Serviços locais de saúde: construção de atores e políticas. Rio de Janeiro : Relume-Dumará, 1993. p. $97-115$

29 ZANETTI, Carlo Henrique Goretti et al. Em busca de um paradigma de programação local em saúde bucal mais resolutivo no SUS. Divulgação em Saúde para Debate, Londrina, n. 13, p. 18-35, jul. 1996.

Endereço para correspondência: Faculdade de Odontologia da UFRGS -

Centro de Pesquisas em Odontologia Social Rua Ramiro Barcelos, $2492-3^{\circ}$ andar sala 301

Porto Alegre/RS

CEP 90035-003 